\title{
The Effect of Striped Patterns on the Visual Evoked Potentials in Patients with Migraine
}

\author{
Hüseyin Büyükgöl*, Emine Genç
}

Department of Neurology, Necmettin Erbakan University, Meram Faculty of Medicine, Akyokus, Meram, Konya, Turkey

*Corresponding author: Hüseyin Büyükgöl, MD, Department of Neurology, Aksaray State Hospital, Aksaray,Turkey, Tel: +90 533614 2789; E-mail: h_buyukgol@hotmail.com

\begin{abstract}
Objective: In this study, we aim to examine the effect of striped patterns on visual evoked potentials in migraine patients.

Materials and methods: This study was performed in the department of neurology with 50 patients (18 - 50 years old) diagnosed with migraine and who had a photophobia. The average age of the patients was 35.16 years and $\% 74$ of them was female. Following the first day of visual evoked potentials shooting, the high-contrast striped patterns were shown to patients for one minute and visual evoked potentials shooting was repeated. Levels of visual evoked potentials were analysed according to the classification and differences were determined. The findings were analysed by using SPSS program Windows 15 version and Kolmogorov Smirnov and Paired Sample tests were used. $\mathrm{P}<0.05$ was considered statistically significant.

Results: Latency of the left eye was found to be significantly higher in all patients $(p<0.05)$. The latency of the left eyes was significantly higher in patients who had migraine more than five years with bilateral pain, who closed the curtain or the light during the attacks, who were uncomfortable with the bright light even without attacks and who had attacks with bright light $(\mathrm{p}<0.05)$. It has been found that the latency level was not related with the number and the duration of attacks, lying under the

duvet and wearing sunglasses $(\mathrm{p}>0.05)$

Conclusion: In conclusion, it has been thought that the latencies prolonged also in the interictal period in light-sensitive individuals due to abnormalities in the information processing of the increasing hyper excitability.
\end{abstract} Received Date: April 09, 2016 Accepted Date: June 21, 2016

Published Date: June 27, 2016

Citation: Büyükgöl, H., et al. The Effect of Striped Patterns on the Visual Evoked Potentials in Patients with Migraine. (2016) Int J Neurol Brain Disord 3(1): 2327.

DOI: $10.15436 / 2377-1348.16 .862$

\section{Introduction}

Migraine is the type of a headache that manifests itself in the form of attacks in the $\% 10-15$ of the population ${ }^{[1]}$. It has been known that migraine occurred due to the neurological, gastrointestinal and autonomic nervous system disorders with different combinations $^{[2]}$. Even though there are hypotheses in order to explain the reasons, the physiopathology of migraine has not yet been clarified.

It has been stated that the visual system had roles in the physiopathology of the migraine because the aura has usually been found as visual and the stimuli led to the onset of migraine attacks and the increased sensitivity to light during an attack in some patients $^{[3,4]}$.

Although the mechanism between the onset of the migraine attack and the light has not yet been explained, it has been supported that there was an increase in the sensitivity to light in the central nervous system ${ }^{[5]}$.

Based on these data, the visual evoked potential studies have been performed to elucidate the physiopathology of migraine, find an objective criterion supporting the diagnosis ${ }^{[6-8]}$. In studies, it has been indicated that there were abnormalities in the responses 
of visual evoked potentials (VEP) and many of the parameters were different ${ }^{[9,10]}$.

According to results of the studies, it has been noticed that the light sensitivity of migraine patients was not questioned and the subgroups were not classified clearly.

The aim of the study was to examine the possible electrophysiological alterations in the visual cortical way.

\section{Patients and Methods}

We have performed our prospective study in Necmettin Erbakan University, Medical Faculty of Meram in the Department of Neurology upon obtaining the ethical approval. We have studied with 50 patients with photophobia and diagnosed with migraine according to ICHD-II criteria. Patients were between 18 - 50 years old. The average age of the patients was 35.16 years and $\% 74$ of the patients was female.

The patients who were diagnosed with another neurological, ocular or systemic disease, who were given prophylactic treatment and who had migraine attack in the last 72 hours and who used any of the pharmacological agents were excluded from the study.

In our study, the detailed anamnesis of patients was recorded and patients were classified according to their light sensitivities. High-contrast striped pattern was shown to patients following the VEP shooting on the first day for one minute and then the VEP shooting was again performed (Figure 1). When the figures were checked approximately $43 \mathrm{~cm}$ far from the monitor, the special frequency and the level of Michelson contrast were detected as 3c.p.d. and 0.7; respectively. VEP levels were analysed according to the classification and the alterations were determined.

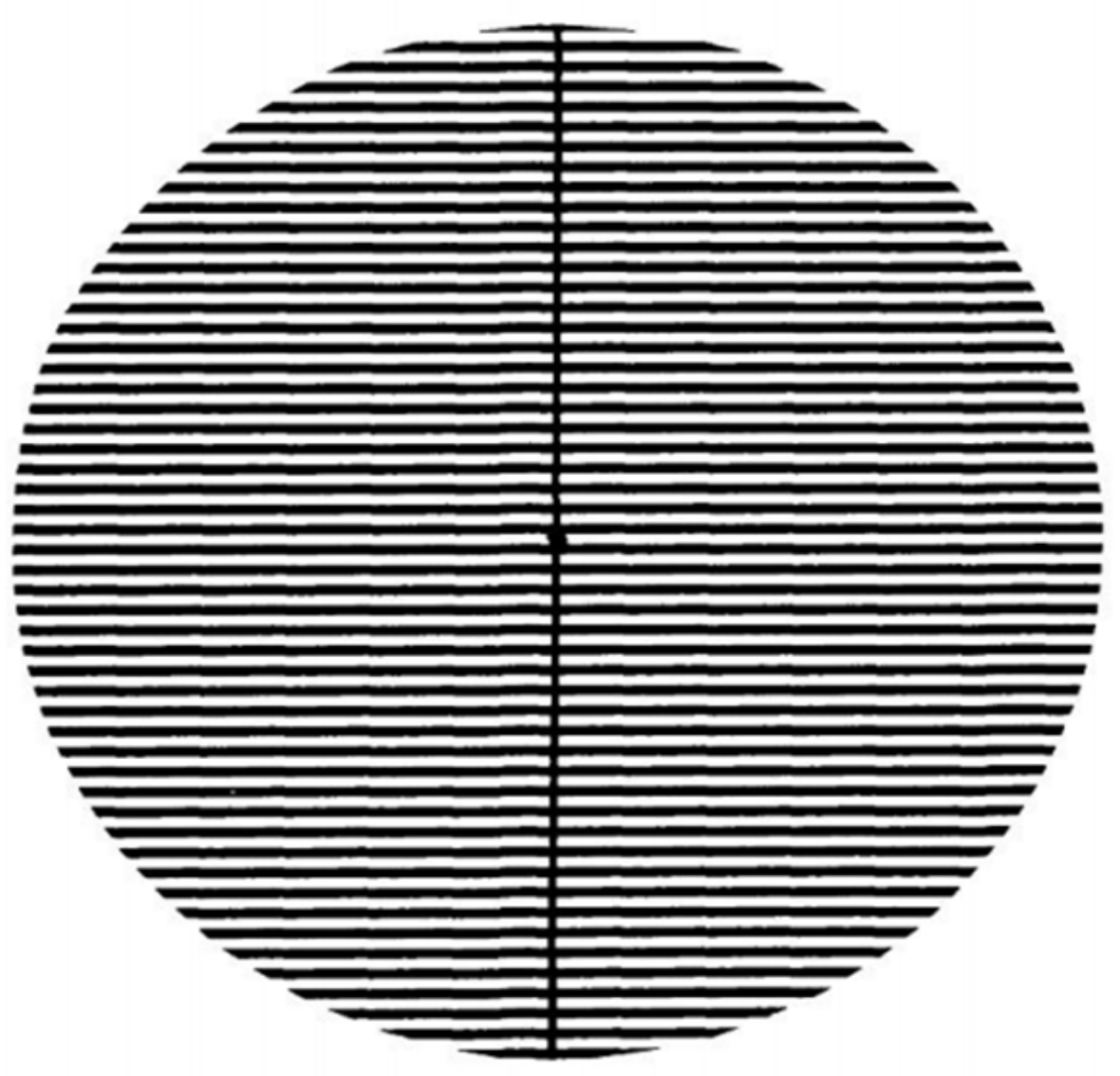

Figure 1: High contrast striped Pattern (square-waveluminance)

Pattern Reversal (PR) VEP analysis was performed in the electrophysiology laboratory in a dimmed and quiet room and when a patient was in a quiet, comfortable position. Scalp was cleaned with acetone and the skin was cleaned with the cleansing gel. According to the international 10 - 20 EEG electrode paste system, active electrode was pasted on the Oz point, reference elec- 
trode was pasted on the Fz point and the earth electrode was pasted on the A1 (left ear) point by using silver disc electrodes. The impedances of the electrodes were kept below $5 \mathrm{k}$ ohm. Electrodes were connected to each other by using Nihon Kohden Neuropack 4 (model MEM-4104K) evoked system. Stimulus (draughtsman design with black-and-white contrast) was given to the patients by showing the VD-40IA video on the monitor $(27 \times 35$ size $)$ with a changing frequency per second. Pupil screen distance was set to 100 $\mathrm{cm}$. The patients fixed their one eye on the small white and unchanging frame at the centre of the monitor. Uniocular bilateral VEP responses were recorded by stimulating primarily the left eye and then the right eye. Cortical responses in Oz were obtained as the mean of 200 VEP responses. The first major negative peak N75 (N1), the second major negative peak N135 (major N2) and P100 positive peak (P1) wave peaks were marked during the PR VEP analysis. The latency values were recorded. By this way, patients were informed about the visual stimulus that could create the headache or the visual illusion.

Findings were analysed by using SPSS program Windows 15 version. Mean, median, standard deviation, and frequency values were used in the descriptive statistical analysis of the data. The distribution of variables was checked by the Kolmogorov Smirnov test. Paired sample test was used in the analysis of the previous and subsequent values of the numerical parametric data. $\mathrm{P}$ $<0.05$ was considered statistically significant.

\section{Findings}

The latency of the left eye was significantly high $(p<0.05)$ and the latency of the right eye was normal $(p>0.05)$ in all patients. The latency of the left eyes was significantly high in patients who had the migraine more than five years and with bilateral pain, who closed the curtain or the light during the attacks, who were uncomfortable with the bright light even without attacks and who had attacks with bright light $(\mathrm{p}<0.05)$. The latency of the right eyes of the patients was normal $(\mathrm{p}>0.05)$. It has been detected that there was no relationship between the level of the latency and the number and the duration of the attacks, lying under the duvet and wearing the sunglasses $(\mathrm{p}>0.05)$

(Table 1).

Table 1: P100 latency characteristics of patients.

\begin{tabular}{|c|c|c|c|c|c|c|c|}
\hline & \multicolumn{3}{|c|}{ Left Eye } & \multicolumn{3}{|c|}{ Right Eye } \\
\hline & & Before shooting & After shooting & $\mathbf{P}$ & Befor shooting & After shooting & $\mathbf{P}$ \\
\hline Average value of all patients & 50 & $106.94 \pm 6.03$ & $107.7 \pm 6.61$ & 0.03 & $107.28 \pm 5.60$ & $107.68 \pm 5.06$ & 0.25 \\
\hline Migraine shorter than 5 years & 16 & $104.75 \pm 5.51$ & $104.87 \pm 5.05$ & 0.86 & $105.68 \pm 7.57$ & $106.12 \pm 6.39$ & 0.35 \\
\hline Migraine longer than 5 years & 34 & $107.97 \pm 6.06$ & $109.11 \pm 6.87$ & 0.03 & $108.02 \pm 4.33$ & $108.41 \pm 4.21$ & 0.51 \\
\hline $\begin{array}{l}\text { Number of attacks less than } 3 \text { per } \\
\text { month }\end{array}$ & 22 & $105.90 \pm 5.59$ & $106.81 \pm 5.02$ & 0.22 & $107.31 \pm 6.46$ & $107.50 \pm 5.83$ & 0.56 \\
\hline $\begin{array}{l}\text { Number of attacks more than } 3 \text { per } \\
\text { month }\end{array}$ & 28 & $107.75 \pm 6.33$ & $108.50 \pm 7.63$ & 0.17 & $107.25 \pm 4.94$ & $107.82 \pm 4.47$ & 0.36 \\
\hline Unilateral pain & 37 & $106.86 \pm 6.29$ & $107.56 \pm 7.07$ & 0.36 & $107.10 \pm 5.96$ & $107.67 \pm 5.46$ & 0.23 \\
\hline Double-sided pain & 13 & $107.15 \pm 5.47$ & $108.30 \pm 5.26$ & 0.03 & $107.76 \pm 4.62$ & $107.69 \pm 3.90$ & 0.73 \\
\hline Pain during less than 24 hours & 14 & $107.57 \pm 5.93$ & $107.64 \pm 5.55$ & 0.96 & $108.50 \pm 7.93$ & $108.85 \pm 6.63$ & 0.52 \\
\hline Pain during more than 24 hours & 36 & $106.69 \pm 6.14$ & $107.80 \pm 7.05$ & 0.29 & $106.80 \pm 4.44$ & $107.22 \pm 4.33$ & 0.41 \\
\hline People who close the lights & 48 & $106.93 \pm 5.93$ & $107.81 \pm 6.60$ & 0.04 & $107.06 \pm 4.87$ & $107.43 \pm 4.53$ & 0.36 \\
\hline People who do not close the lights & 2 & $107.00 \pm 11.31$ & $106.50 \pm 9.19$ & 0.65 & $112.50 \pm 19.09$ & $113.50 \pm 14.84$ & 0.65 \\
\hline People who close the curtains & 36 & $107.50 \pm 5.94$ & $108.63 \pm 6.81$ & 0.03 & $108.08 \pm 4.68$ & $108.25 \pm 4.46$ & 0.89 \\
\hline $\begin{array}{l}\text { People who do not close the cur- } \\
\text { tains }\end{array}$ & 14 & $105.50 \pm 6.23$ & $105.50 \pm 5.65$ & 0.87 & $105.21 \pm 7.28$ & $106.21 \pm 6.30$ & 0.05 \\
\hline People who lie under duvet & 31 & $105.90 \pm 4.98$ & $106.51 \pm 4.89$ & 0.15 & $106.61 \pm 4.79$ & $106.80 \pm 4.23$ & 0.66 \\
\hline People who do not lie under duvet & 19 & $108.63 \pm 7.26$ & $109.78 \pm 8.48$ & 0.24 & $108.36 \pm 6.72$ & $109.10 \pm 6.03$ & 0.28 \\
\hline People who wear sunglasses & 28 & $106.75 \pm 5.07$ & $107.35 \pm 5.27$ & 0.16 & $107.82 \pm 4.58$ & $107.64 \pm 3.87$ & 0.61 \\
\hline People who do not wear sunglasses & 22 & $107.18 \pm 7.19$ & $108.27 \pm 8.10$ & 0.22 & $106.89 \pm 6.73$ & $107.72 \pm 6.36$ & 0.22 \\
\hline $\begin{array}{l}\text { People who are not comfortable } \\
\text { with bright light }\end{array}$ & 32 & $107.18 \pm 6.54$ & $108.34 \pm 7.34$ & 0.04 & $107.59 \pm 5.92$ & $108.09 \pm 5.16$ & 0.33 \\
\hline $\begin{array}{l}\text { People who are comfortable with } \\
\text { bright light }\end{array}$ & 18 & $106.50 \pm 5.15$ & $106.72 \pm 5.07$ & 0.77 & $106.72 \pm 5.10$ & $106.94 \pm 4.94$ & 0.77 \\
\hline $\begin{array}{l}\text { People whose attacks start with } \\
\text { bright light }\end{array}$ & 27 & $106.92 \pm 6.60$ & $108.18 \pm 7.74$ & 0.03 & $106.92 \pm 5.59$ & $107.59 \pm 5.00$ & 0.23 \\
\hline $\begin{array}{l}\text { People whose attacks do not start } \\
\text { with bright light }\end{array}$ & 23 & $106.95 \pm 5.43$ & $107.26 \pm 5.10$ & 0.84 & $107.69 \pm 5.71$ & $107.78 \pm 5.22$ & 0.78 \\
\hline
\end{tabular}




\section{Discussion}

Migraine is an idiopathic and recurrent headache syndrome that occurs with attacks and the duration of the pain changes 4 to 72 hours $^{[11]}$.

Photophobia is one of the symptoms of the migraine attacks and it can emerge as a result of the meningeal irritation and ocular pathologies ${ }^{[12]}$. It can be defined as the sore hypersensitivity reaction that occurs with light ${ }^{[12]}$. It has been thought that the visual system could have roles in the physiopathology of migraine because it has been known that the light reactions were observed in the steps of migraine ${ }^{[3,4,13]}$.

Latency level depends on many factors such as stimulus frequency, contrast, fixation, stimulus intensity, pupil size, gender and age ${ }^{[14]}$ In our study, the elongation in the P100 latency was detected in the left eye. We can conclude that the delay of the latency in the right eye happens depending on the frequency and the intensity of the stimuli as a result of the synaptic fatigue in the visual field during the first measurement. Besides, it should be noted that the efficiency of the stimulus can be lost in case of the extension of time for the right eye shooting. Therefore, the effect on the visual ways was significant in the right eye recordings where as the recordings of the right eye might not be significant following the pattern of stripes watching.

The relationship between the migraine and the VEP has been examined in many studies and the association between VEP latencies have been shown ${ }^{[9,10]}$. Oelkers et $\mathrm{al}^{[15]}$ have shown that the spatial frequency (the size of the squares used in the PR VEP) had effects on the VEP components in migraine patients. They have also supported the idea that the horizontal plane processed the information whereas the vertical plane provided the luminance. In the same study, Oelkers et al ${ }^{[15]}$ have indicated that there was a significant increase in the latency levels upon stimulus. Coleston et $\mathrm{al}^{\left[{ }^{[16]}\right.}$ have detected that the spatial and temporal visual information was slowly processed in the precortical area in migraine patients. Consistent with the literature, we conclude that the stimuli leads to the elongation of the latency in migraine patients.

In one review, it has been notified that the edema and ischemia fields developed in the brain tissue during migraine attacks $^{[17]}$. Lauritzen et $\mathrm{a}^{[18]}$ have shown that there was a $\% 25-30$ decline in regional blood flow in the pre-migraine period with aura. Chronicle and Mulleners have explained that the reason for the VAS elongation during the attack-free periods was the hyper excitability occurred because of the attack periods or the interneuron loss due to drug use ${ }^{[19]}$. In our study, we have detected the elongation in the latency period of the patients who suffered from migraine more than five years with bilateral pain.

The drugs used in the treatment of the migraine, attacks and the ischemia/interneuron loss depending on the edema can occur due to the hyper excitability. Furthermore, it is possible that the edema and ischemia area can be wide in the bilateral involvements.

There is a light sensitivity in migraine patients even in the attack-free periods. ${ }^{[13,20]}$. Khalil et al ${ }^{[21]}$ have performed a study in which they measure the VEP levels of migraine patients and they have shown that there was a pathology in the processing of the visual information. İşler have stated that there was a neuronal hyper excitability in migraine patients and therefore, patients showed extra sensitivity to light and other stimuli ${ }^{[20]}$. It has been shown that the electro physiologically detectable hyper excitability status was shown to be the basis of the abnormal VEP response ${ }^{[2]}$. Shibata et al. have supported the idea that there was an increase in the N135 latency and the amplitude in the high-contrast pattern VEP applied in migraine patients ${ }^{[23]}$. Moreover, they have stated that the high contrasts easily revealed the abnormal cortical activity in the interictal periods due to the abnormality of the information processing in the visual cortex. In our study, we have detected the significant elongations in the latency periods of the light-sensitive individuals. These elongations seemed to support the pathology related to visual information processing in the migraine patients with the photophobia in the interictal period. Furthermore, in some of the migraine patients, it could be possible that the exposure to the stimulus just before the PRVEP shooting led to elongate the p100 latencies compared to the patients diagnosed with migraine.

\section{Conclusion}

All in all, it has been thought that the hyper excitability can lead to the elongation in latency depending on the abnormalities in processing information in the light sensitive patients also in the interictal period. The further electrophysiological studies will contribute to the elucidation of the path physiology of migraine. 


\section{References}

1. Yücel, Y. Migren Baş Ağrısında Tanı Ve Tedavi Yaklaşımları. (2008) Dicle Tıp Dergisi 35(4): 281-286.

2. Lipton, R.B., Stewart, W.F., Diamond, S., et al. Prevalence and burden of migraine in the United States: data from the American Migraine Study

II. (2001) Headache 41(7): 646-657.

3. Main, A., Dowson, A., Gross, M. Photophobia and phonophobia in migraineurs between attacks. (1997) Headache 37(8): 492-495.

4. Woodhouse, A., Drummond, P.D. Mechanisms of increased sensitivity to noise and light in migraine headache. (1993) Cephalalgia 13(6): 417421.

5. Schoenen, J. Cortical electrophysiology in migraine and possible pathogenetic implications. (1998) Clin Neurosci 5(1): 10-17.

6. Mulleners, W.M., Chronicle, E.P., Palmer, J.E., et al. Visual cortex excitability in migraine with and without aura. (2001) Headache 41(6): 565572.

7. Afra, J., Proietti, C., Sandor, P.S., et al. Comparison of visual and auditory evoked cortical potentials in migraine patients between attacks. (2000) Clin Neurophysiol 111(6): 1124-1129.

8. Shiabata, K., Yamane, K., Iwata, M., et al. Evaluating the effect of spatial frequency on migraines by using pattern reversal evoked potentials. (2005) Clin Neurophysiol 116(9): 2220-2227.

9. Lahat, E., Nadir, E., Barr, J., et al. Visual evoked potentials: a diagnostic test for migraine headache in children. (1997) Dev Med Child Neurol 39(2): 85-87.

10. Lahat, E., Barr, J., Barzilai, A., et al. Visual evoked potentials in the diagnosis of headache before 5 years of age. (1999) Eur J Pediatr 158(11): 982-985.

11. Silberstein, S.D., Lipton, R.B., Goadsby, P.J. Klinik uygulamada Baş Ağrısı, Türkçe Çeviri Editörü Ertas M. 2004; 1-113.

12. Moulton, E.A., Becerra, L., Borsook, D. An fMRI Case Report of Photophobia: Activation of the Trigeminal nociceptive Pathway. (2009) Pain 145(3): 358-363.

13. Choi, J.Y., Oh, K., Kim, B.J., et al. Usefulness of a photophobia questionnaire in patients with migraine. (2009) Cephalalgia 29(9): 953-959.

14. Altenmüller, E.O., Gerloff, C. Psychophysiology and the EEG. In: Niedermayer E, Lopes da Silva F. Eds. Electroencephalography: Basic Principles, Clinical Aplications, and Related Fields, 4th Ed., Baltimore: Williams\&Wilkins, 1999:637-655.

15. Oelkers, R., Grosser, K., Lang, E., et al. Visual evoked potentials in migraine patients: Alterations depend on pattern spatial frequency. (1999) Brain 122(pt 6): 1147-1155.

16. Coleston, D.M., Chronicle, E., Ruddock, K.H., et al. Precortical dysfunction of spatial and temporal visual processing in migraine. (1994) J Neurol Neurosurg Psychiatry 57(10): 1208-1211.

17. Okan, M., Özdemir, H. Çocuklarda Başağrısı. (2003) Güncel Pediatri 1 : 10-18.

18. Lauritzen, M., Skyhoj, O.T., Lassen, N.A. Changes in regional blood flow during the course of classic migraine attacks. (1983) AnnNeurol 13(6): 633-635.

19. Chronicle, E., Mulleners, W. Might migraine damage the brain? (1994) Cephalalgia 14(6): 415-418.

20. İşler, H. Retrospect: the history of thought about migraine from Areteusto 1920. In: Blau J (ed). Migraine: Clinical, Therapeutic, Conceptual and Research Aspects. London: Chapmanand Hall Medical; 1987: 659-674.

21. Khalil, N., Anderson, L.D. Long term decline of P100 amplitude in migraine with aura. (2000) J Neurol Neurosurg Psychiatry. 69(4): 507-511.

22. Diener, H.C., Scholz, E., Dichgans, J., et al. Central effects of drugs used in migraine prophylaxis evaluated by visual evoked potentials. (1989) Ann Neurol 25(2): 125-130.

23. Shibata, K., Osawa, M., Iwata, M. Simultaneous recording of pattern reversal electroretinograms and visual evoked potentials in migraine. (1997) Cephalalgia 17(7): 742-747.

Online ISSN: $2377-1348$

Journal Title: International Journal Neurology and Brain Disorders Journal Short Name: Int J Neurol Brain Disord
Ommega Online Publishers

E-mail: neurology@ommegaonline.com

Website: www.ommegaonline.org 